\title{
Review
}

\section{Circulating liver-specific microRNAs in cynomolgus monkeys}

\author{
Takuma Iguchi1 ${ }^{*}$, Ken Sakurai1, Satoshi Tamai1, and Kazuhiko Mori ${ }^{1}$ \\ ${ }^{1}$ Medicinal Safety Research Laboratories, Daiichi Sankyo Co., Ltd., 1-16-13 Kita-Kasai, Edogawa-ku, Tokyo 134-8630, Japan
}

\begin{abstract}
Circulating microRNAs (miRNAs) can potentially be used as sensitive and specific biomarkers for tissue injury. However, the usefulness of circulating miRNAs as safety biomarkers in nonclinical toxicological studies using nonhuman primates is debatable owing to the limited information on organ-specific miRNAs. Therefore, a systematic investigation was performed to address this point. We identified organ-specific miRNAs from cynomolgus monkeys by next-generation sequencing analysis, which revealed that miR-122 was only abundant in the liver, whereas miR-192 was abundant in the liver, stomach, intestines, and kidney. The sequences of these miRNAs were identical to their human counterparts. Next, the absolute miR-122 and miR-192 levels were qualified by quantitative reverse transcription polymerase chain reaction (RT-qPCR) to determine the circulating levels of the miRNAs. No significant differences in the levels of circulating miRNAs between sexes were noted, and there was greater interindividual variation in miR-122 (20-fold variation) than in miR-192 (8-fold variation), based on their dynamic ranges. Finally, we evaluated the fluctuation in circulating liverspecific miRNAs in a monkey model of acetaminophen-induced hepatotoxicity. Acetaminophen with L-buthionine-(S,R)-sulfoximine induced hepatotoxicity in all the animals, which was characterized histopathologically by centrilobular necrosis and vacuolation of hepatocytes. Circulating miR-122 and miR-192 levels increased more than ALT levels after 24 h, indicating that circulating miR-122 and miR-192 may serve as sensitive biomarkers for the detection of hepatotoxicity in cynomolgus monkeys. This review describes the fundamental profiles of circulating liver-specific miRNAs in cynomolgus monkeys and focusses on their organ specificity, circulating levels, and fluctuations in drug-induced hepatotoxicity. (DOI: 10.1293/tox.2017-0036; J Toxicol Pathol 2018; 31: 3-13)
\end{abstract}

Key words: cynomolgus monkeys, microRNA, next-generation sequencing, drug-induced liver injury

\section{Introduction}

MicroRNAs (miRNAs) are small (19-24 nucleotides) noncoding RNAs that regulate gene expression at the posttranscriptional level by repressing or degrading target mRNA. MiRNAs play crucial roles in diverse biological processes such as mediating cell cycle arrest and apoptosis, differentiation, cellular proliferation, and development ${ }^{1}$. Over the past few years, interest in circulating miRNAs has increased, and researchers have focused on exploring their potential as biomarkers. This is because circulating miRNAs have several advantages over conventional biomarkers. For instance, miRNAs are biologically stable in body fluids even under harsh conditions such as extreme temperature, low/high $\mathrm{pH}$, repeated freeze-thaw cycles, extended storage at room temperature, and high endogenous ribonuclease activity ${ }^{2,3}$. Moreover, their expression patterns make them

Received: 8 June 2017, Accepted: 17 August 2017

Published online in J-STAGE: 8 September 2017

*Corresponding author: T Iguchi

(e-mail: iguchi.takuma.kz@daiichisankyo.co.jp)

C2018 The Japanese Society of Toxicologic Pathology

This is an open-access article distributed under the terms of the Creative Commons Attribution Non-Commercial No Derivatives
(c) (by-nc-nd) License. (CC-BY-NC-ND 4.0: https:// (c) attractive biomarkers because some circulating miRNAs originate from tissues or cells where miRNAs are highly or specifically expressed ${ }^{4}, 5$. Consequently, there has been an increasing number of clinical and nonclinical studies exploring miRNAs as biomarkers for diseases including cancers $^{6,7}$.

MiRNAs have potential for use as translational biomarkers because the sequences of most miRNAs are conserved among animal species ${ }^{8}$. The high degree of sequence homology raises the possibility that their distribution and function are preserved across species, and the release of miRNAs from tumors or injured cells into the plasma may be a common mechanism. For example, miR-122 is well conserved and has been identified as the most abundant liver-specific miRNA; levels of plasma miR-122 increase following liver injury in both rodents and humans ${ }^{9}, 10$.

The cynomolgus monkey (Macaca fascicularis) is commonly used for nonhuman primate experiments, especially in the field of toxicology. Cynomolgus monkeys are of particular interest for use as an animal model of human biology because they are anatomically, physiologically, and genetically closer to humans than other laboratory animals such as rodents ${ }^{11,12}$ and have several drug-metabolizing enzymes that are similar to those found in humans ${ }^{13}$. However, little is known with regard to circulating organ-specific miRNAs in cynomolgus monkeys to our knowledge.

The liver is a primary target of drug toxicity because it 
metabolizes exogenous compounds into reactive intermediates that can cause acute liver failure. Drug-induced liver injury (DILI) is the leading cause for failures in drug development or drug withdrawal from the market ${ }^{14}$. Circulating liver-specific miR-122 and/or miR-192 have been proposed as sensitive and specific biomarkers for liver injury because they increased earlier and at lower doses compared with alanine aminotransferase (ALT) in several types of DILI induced by acetaminophen (APAP), alpha-naphthylisothiocyanate (ANIT), or carbon tetrachloride in mice ${ }^{10}$, rats ${ }^{15,16}$, and humans 9,17 .

Owing to the limited information on organ-specific miRNAs, the use of circulating miRNAs as safety biomarkers in nonclinical toxicological studies of cynomolgus monkeys remains challenging. In this review, we have highlighted a systematic approach to gaining a better understanding of the fundamental profiles of circulating miRNAs as safety biomarkers in cynomolgus monkeys. First, we identified organ-specific miRNAs by next-generation sequencing (NGS) analysis. Next, we quantified absolute values of miR122 and miR-192 levels by quantitative real-time reverse transcription polymerase chain reaction (RT-qPCR), using a TaqMan microRNA assay. Finally, we evaluated the fluctuation of circulating liver-specific miRNAs in a monkey model of APAP-induced hepatotoxicity.

\section{Identification and Profiling of Liver-specific miRNAs in Cynomolgus Monkeys}

\section{Identification of liver-specific miRNAs by NGS analy- sis}

Investigating expression patterns of miRNAs is informative to select specific biomarkers for tissue injuries because miRNAs are released into extracellular fluid from the cytoplasm of damaged cells as by-products at variable levels. Therefore, organ-specific circulating miRNAs can be traced to the organ of origin. Although the mechanism underlying the elevation of circulating miRNAs remains unclear, circulating levels of liver-, muscle-, and heart-specific miRNAs are reported to increase with toxicity in those tissues ${ }^{4,5,18}$. NGS analysis has emerged as a powerful tool for revealing novel or homologous sequences of unknown miRNAs, because this technology provides sequence data at single-base resolution without prior sequence information. In addition, NGS analysis can provide relative expression data for thousands of miRNAs with greater sensitivity and dynamic range than microarray-based platforms ${ }^{19}$.

Using this technology, mature miRNAs in the kidneys ${ }^{20}$ or testes ${ }^{21}$ of cynomolgus monkeys have been identified. More importantly, their miRNAs have high homology with those of rhesus macaques and humans. We have evaluated preferentially expressed miRNAs from different organs to identify other organ-specific miRNAs and their predominant sequences in cynomolgus monkeys ${ }^{22}$.

We used the NGS data for 27 tissues and organs from male and female cynomolgus monkeys ( $n=2 /$ sex), namely the adrenal gland, aorta, eye, heart (left ventricular wall and papillary muscle), intestine (colon, duodenum, jejunum including the ileum, and rectum), kidney (cortex, medulla, and papilla), liver, lung, ovary (from females), plasma, pancreas, sciatic nerve, skeletal muscle (rectus femoris and soleus), skin, spleen, stomach, testis (from males), trachea, urinary bladder, and uterus (from females). The expression levels in each tissue or organ were normalized from the raw count data to reads per million (rpm). The percentage of miRNA expression in the target organ was calculated by dividing the sum of the counts (rpm) in all organs by the counts (rpm) in each tissue or organ. To assess the organ specificity of each miRNA, the counts for the sectioned organs, including the heart, intestine, kidney, and skeletal muscle, were expressed as their averages.

More than 1000 mature miRNAs were filtered using the following criterion: the sum of the expression levels of the miRNA in all organs exceeds $500 \mathrm{rpm}$. The expression ratio to total rpm of each miRNA with the top five most specific organs is shown in Table 1. As a result, miR-122 was identified as a liver-specific miRNA (99.8\%), and other organ-specific miRNAs that showed more than $80 \%$ specificity in their predominant organs were also identified for the heart (miR-208a, miR-499a, and miR-208b), skeletal muscle (miR-206 and miR-133b), testis (miR-508), skin (miR-203a), intestine (miR-215), sciatic nerve (miR-338), and eye (miR124, miR-183, miR-184, miR-96, and miR-211). Because miR-192 has been reported as a liver-specific biomarker for liver injury in rodents ${ }^{10}$ and humans ${ }^{9}$, the top five liver-specific miRNAs were further evaluated by their count values in other organs (Fig. 1). Thus, miR-122 was expressed at extremely high levels in the liver compared with in other organs, whereas miR-192 was expressed not only in the liver but also in the stomach, intestines (duodenum, jejunum, and colon), and kidney at relatively high levels. Furthermore, in the cynomolgus monkeys, both miR-122 and miR-192 exhibited $100 \%$ sequence homology with the corresponding mature human miRNAs, respectively.

The expression of miR-192 in multiple organs is not a unique feature of cynomolgus monkeys, because similar results have been reported in rats ${ }^{23}$ and $\operatorname{dogs}^{24}$. Tian et al. ${ }^{25}$ found that miR-192 was highly enriched in the rat kidney cortex, and Zhang et al. ${ }^{7}$ reported that the circulating miR192 level increased as a result of renal ischemia reperfusion injury in rats; therefore, the source of miR-192 should be interpreted carefully when its circulated level is elevated.

\section{Profiling of circulating liver-specific miRNAs}

RT-qPCR is one of the most common methods used to assess individual target miRNAs ${ }^{26}$. In general, miRNA expression is measured relative to a reference sample. This approach is usually appropriate when an examination of the physiological changes in target gene expression is required. However, absolute quantification is preferred for a comprehensive assessment of the basal expression level because it facilitates better statistical analysis.

We evaluated the levels of selected circulating miRNAs in 25 male and 25 female 3- to 4-year-old cynomolgus 
Table 1. Top Five Organ-specific MicroRNAs (miRNAs) in Cynomolgus Monkeys Identified by Next-generation Sequencing (NGS)

\begin{tabular}{|c|c|c|c|c|c|c|c|}
\hline \multicolumn{2}{|c|}{ Liver } & \multicolumn{2}{|c|}{ Heart } & \multicolumn{2}{|c|}{ Skeletal muscle } & \multicolumn{2}{|c|}{ Kidney } \\
\hline miRNAs & $(\%)$ & miRNAs & $(\%)$ & miRNAs & $(\%)$ & miRNAs & $(\%)$ \\
\hline miR-122 & 99.8 & miR-208a & 98.7 & miR-206 & 99.2 & miR-196a & 25.3 \\
\hline miR-3745 & 57.1 & miR-499a & 89.2 & miR-133b & 84 & miR-10b & 20.8 \\
\hline miR-4532 & 46.1 & $\operatorname{miR}-208 b$ & 84.7 & miR-133c & 76.9 & miR-10a & 19.7 \\
\hline miR-885 & 42.9 & miR-4053 & 47.9 & miR-133a & 67.9 & miR-363 & 18.9 \\
\hline miR-192 & 41.4 & miR-344 & 38.8 & miR-1 & 58.4 & miR-10c & 18.4 \\
\hline \multicolumn{2}{|c|}{ Testis } & \multicolumn{2}{|c|}{ Lung } & \multicolumn{2}{|c|}{ Skin } & \multicolumn{2}{|c|}{ Intestine } \\
\hline miRNAs & $(\%)$ & miRNAs & $(\%)$ & miRNAs & $(\%)$ & miRNAs & $(\%)$ \\
\hline miR-508 & 87.4 & miR-223 & 38.8 & miR-203a & 87 & miR-215 & 88.4 \\
\hline miR-202 & 69.8 & miR-451a & 23.5 & miR-205 & 79 & miR-5115 & 60.9 \\
\hline $\operatorname{miR}-449 a$ & 46.6 & miR-144 & 22.1 & $\mathrm{miR}-320 \mathrm{~b}$ & 44.9 & miR-4745 & 54.5 \\
\hline miR-34c & 38.7 & miR-126 & 21.8 & miR-2904 & 25.9 & miR-4492 & 53.2 \\
\hline miR-2779 & 15.1 & miR-30a & 19.6 & miR-3195 & 19.2 & miR-4292 & 52.9 \\
\hline \multicolumn{2}{|c|}{ Pancreas } & \multicolumn{2}{|c|}{ Sciatic nerve } & \multicolumn{2}{|c|}{ Eye } & \multicolumn{2}{|c|}{ Plasma } \\
\hline miRNAs & $(\%)$ & miRNAs & $(\%)$ & miRNAs & $(\%)$ & miRNAs & $(\%)$ \\
\hline miR-148a & 51.5 & miR-338 & 86.4 & miR-124 & 98.1 & miR-4515 & 21.1 \\
\hline $\operatorname{miR}-375$ & 48.8 & miR-584 & 67.8 & miR-183 & 93.7 & miR-486 & 20.7 \\
\hline miR-1434 & 25 & miR-363 & 45.3 & miR-184 & 90.7 & miR-4634 & 16.4 \\
\hline miR-200c & 21.9 & miR-138 & 34 & miR-96 & 89.7 & miR-1386 & 10 \\
\hline miR-381 & 17.1 & miR-196a & 28.9 & miR-211 & 89.2 & miR-31 & 6.4 \\
\hline
\end{tabular}

The expression levels in each tissue or organ were normalized from the raw count data to reads per million (rpm). The percentage of miRNA expression in the target organs was calculated by dividing the sum of the counts (rpm) in all organs by the counts (rpm) in each tissue or organ. To assess the organ specificity of each miRNA, the counts for the sectioned organs, including the heart, intestine, kidney, and skeletal muscle, were expressed as their averages.
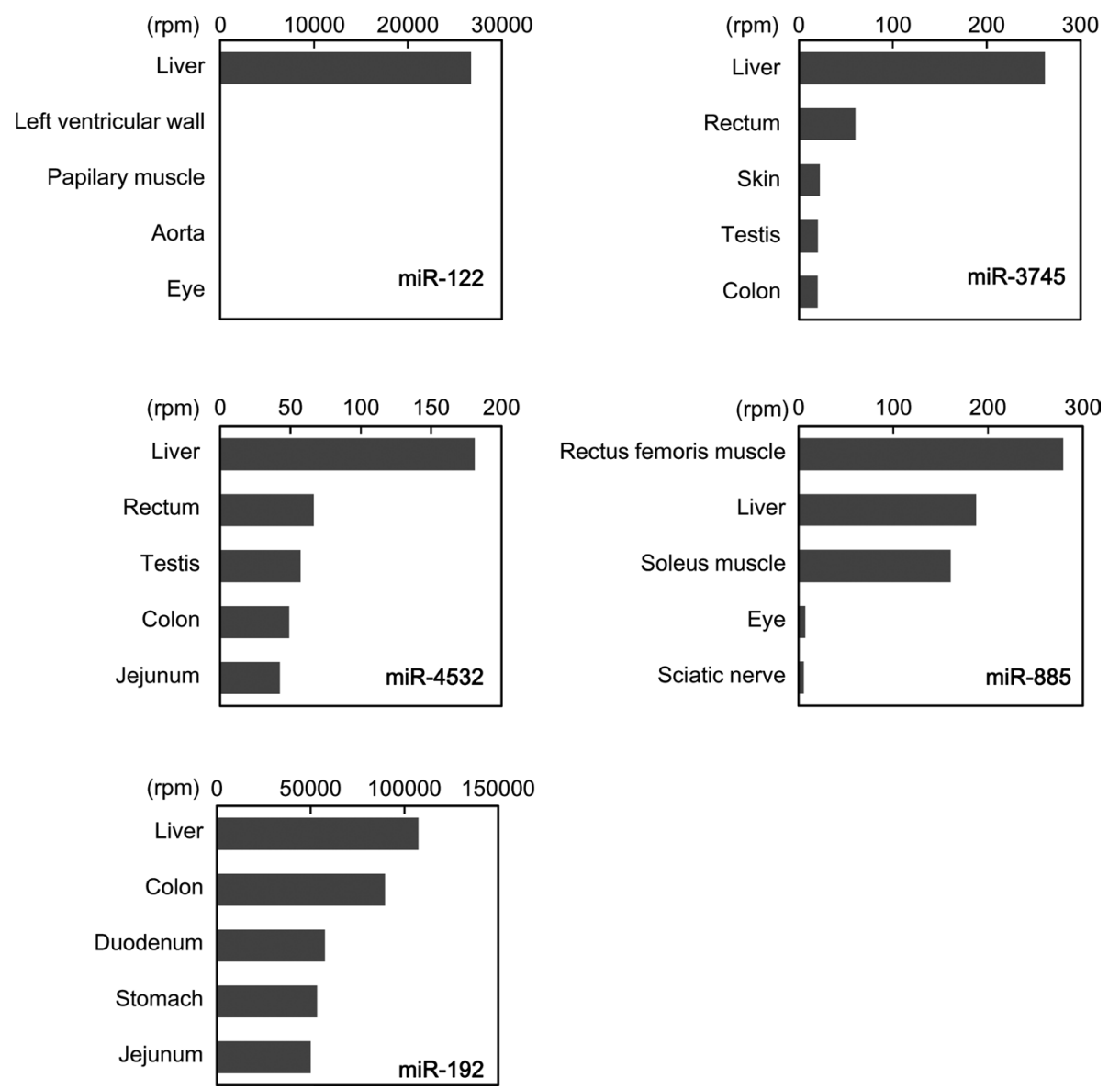

Fig. 1. Expression profiles of selected microRNAs (miRNAs) in cynomolgus monkeys identified by next-generation sequencing (NGS). The expression levels in each tissue or organ were normalized from the raw count data to reads per million (rpm). The $\mathrm{x}$-axis expresses reads per million. 

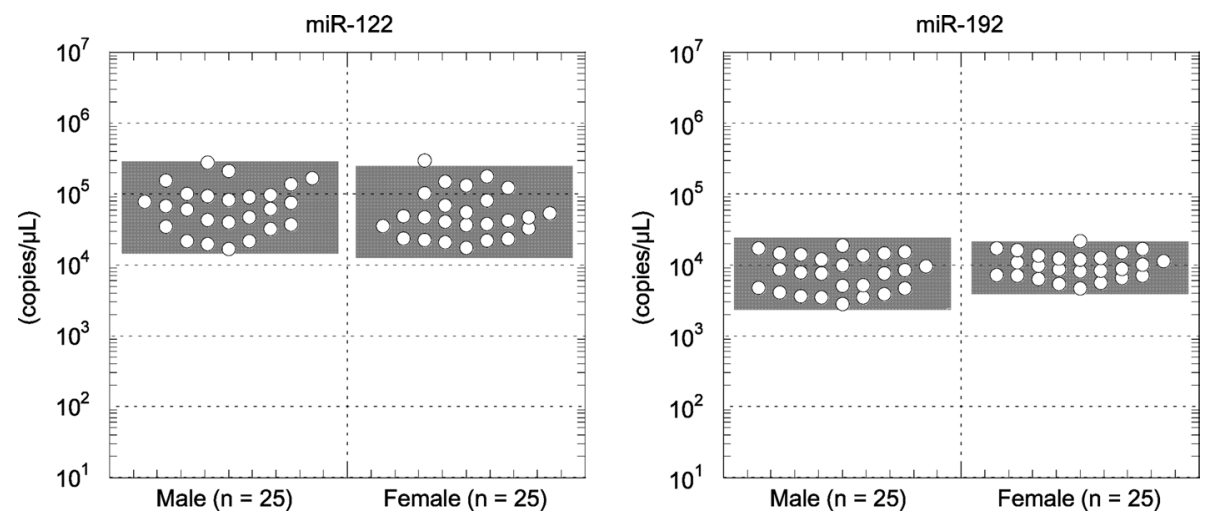

Fig. 2. Circulating levels of liver-specific microRNAs (miRNAs) in male and female monkeys ${ }^{22}$. The expression levels of the miRNAs are represented by dot plots. Differences were analyzed by the Mann-Whitney U-test. The ranges of the means $\pm 2 \mathrm{SD}$ from the male or female data are represented by gray boxes.

Table 2. Statistical Values for the Plasma Levels of Liver-specific MicroRNAs (miRNAs)22

\begin{tabular}{|c|c|c|c|c|c|c|}
\hline \multirow{2}{*}{$\begin{array}{l}\text { miRNA } \\
\text { Sex }\end{array}$} & \multicolumn{3}{|c|}{ miR-122 } & \multicolumn{3}{|c|}{ miR-192 } \\
\hline & M & $\mathrm{F}$ & $M+F$ & M & $\mathrm{F}$ & $\mathrm{M}+\mathrm{F}$ \\
\hline $\mathrm{N}$ & 25 & 25 & 50 & 25 & 25 & 50 \\
\hline Mean $\left(\times 10^{3}\right.$ copies $\left./ \mu \mathrm{L}\right)$ & 63.4 & 51.4 & 57.1 & 7.5 & 9.7 & 8.5 \\
\hline Mean $-2 \mathrm{SD}\left(\times 10^{3}\right.$ copies $\left./ \mu \mathrm{L}\right)$ & 14 & 11.5 & 12.7 & 2.3 & 4.3 & 3 \\
\hline Mean $+2 \mathrm{SD}\left(\times 10^{3}\right.$ copies $\left./ \mu \mathrm{L}\right)$ & 288 & 229 & 257 & 24.3 & 21.9 & 23.9 \\
\hline Dynamic range & 20.6 & 19.9 & 20.2 & 10.4 & 5.1 & 7.9 \\
\hline
\end{tabular}

The mean, and the value for two standard deviations below and above the mean, were determined after logarithmic transformation. The dynamic range was calculated by the difference between mean -2 SD and mean +2 SD. M, male; F, female.

monkeys. Whole blood samples (1 $\mathrm{mL}$ per sampling point) were collected from the femoral vein into tubes containing ethylenediaminetetraacetic acid (EDTA) 2K (Microtainer, Japan Becton Dickinson Company, Ltd., Tokyo, Japan). The absolute values of circulating miRNAs were quantified by a TaqMan microRNA assay, as described previously 22 .

\section{Quality assessment of RT-qPCR performance}

We evaluated the efficiency of sample processing in our laboratory using the quantification cycle $(\mathrm{Cq})$ values of Spiked-In cel-miR-23822. In our assay method, the technical variation was less than 2.5 -fold, the lower limit of quantification (LLOQ) value was $10^{2}$ copies $/ \mu \mathrm{L}$ for miR-122 and miR-192, and the average amplification efficiency was approximately $90 \%$, with a correlation coefficient $\left(\mathrm{R}^{2}\right)$ of the standard curves ranging from 0.998 to $1.000^{22}$. Although the technical variation and PCR efficiency for the data have rarely been highlighted, this information is important because some data, including those described below, exhibit both technical and biological variations.

\section{Expression profiles of liver-specific miRNAs}

We determined the plasma levels of miR-122 and miR192 based on the assay platform described above. The original data were positively skewed; therefore, a logarithmic transformation was applied to normalize the distribution, as reported by Bland et al. ${ }^{27}$. The means and standard devia- tions (SDs) were transformed back into the original scale. The range of the mean $\pm 2 \mathrm{SD}$ was thereby determined to be the "reference range." To evaluate the interindividual variation, the values for two standard deviations below and above the mean were defined as the "dynamic range" in the study. There was no differences in the miRNA levels between the sexes (Fig. 2, Table 2), and miR-122 had a higher mean plasma level and a higher dynamic range than miR-192. We also evaluated intraindividual variations in the expression of each circulating miRNA; however, at different time points, these variations were almost within the reference range (Fig. 3).

Our comprehensive assessment using samples from 50 animals has also provided a more rigorous statistical analysis of the extent of the dynamic range. However, a current limitation is that a standardized internal control for normalization has not yet been established. In this respect, external reference controls have been proposed to compare the results of studies conducted in various laboratories incorporating different platforms 28,29 . Our RT-qPCR data revealed that miR-122 and miR-192 showed only 20-fold and 8-fold variation, respectively. In another study using human serum or plasma from healthy subjects $(\mathrm{n}=25)^{9}$, the dynamic ranges of miR-122 and miR-192 were estimated at 22-fold and 15 -fold, respectively. This similarity suggests that the dynamic range of the miRNAs is conserved between monkeys and humans. 

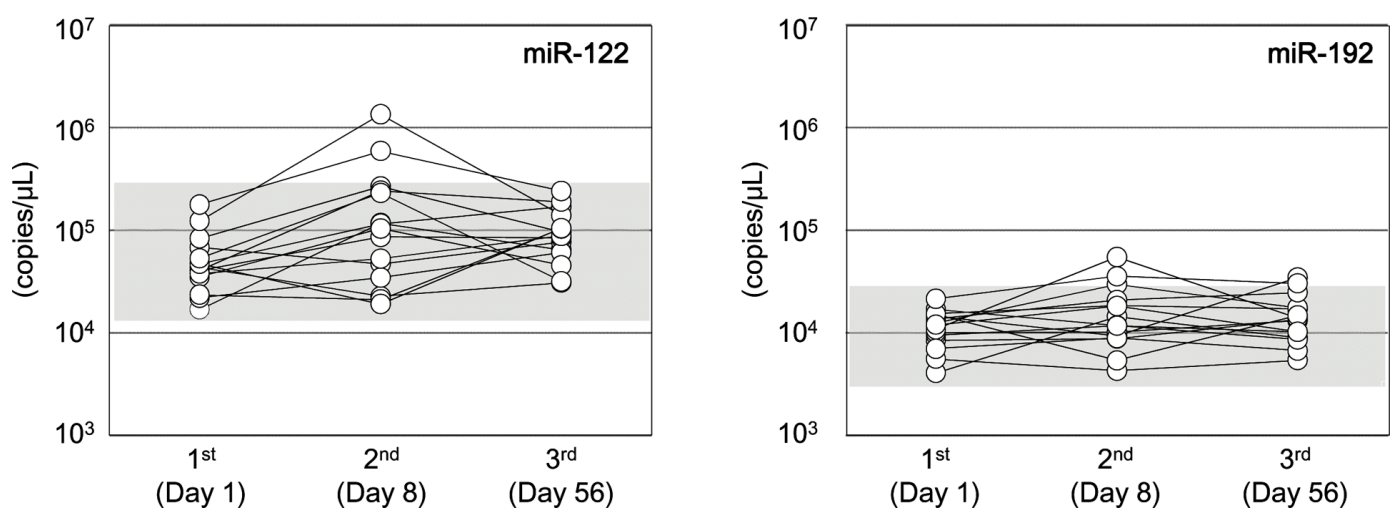

Fig. 3. Intraindividual variations in the expression of each circulating microRNA (miRNA). The plasma levels of the miRNAs on different sampling days (Day 1, Day 8, and Day 56) in the same animal are shown. The ranges of the means \pm 2 SD calculated from 50 cynomolgus monkeys are represented by gray boxes.

\section{Circulating miR-122 and miR-192 as Potential Hepatotoxicity Biomarkers}

\section{Establishment of an APAP-induced hepatotoxicity model in cynomolgus monkeys}

Rodent models have been used extensively in preclinical settings to investigate the mechanisms underlying DILI and potential translational biomarkers for DILI diagnosis. However, in several cases, the phenotypic outcome of hepatotoxic signals differs between rodents and humans, and this is associated with contributing factors including the dose level, the pharmacokinetic profile, or pathogenesis ${ }^{30,31}$. The cynomolgus monkey is widely used as a nonhuman primate in regulatory toxicity testing for drug development. However, little is known about drug-induced hepatotoxic signatures or circulating hepatic biomarker profiles in cynomolgus monkeys. Therefore, we established a monkey model of APAP-induced hepatotoxicity to attain a better understanding of the fluctuation of circulating miRNAs as potential hepatotoxic biomarkers ${ }^{32}$.

Because an in vitro study revealed the low susceptibility of monkey hepatocytes to APAP-induced hepatotoxicity ${ }^{33}$, we selected a combinational dose regimen of APAP with the glutathione biosynthesis inhibitor L-buthionine$(\mathrm{S}, \mathrm{R})$-sulfoximine (BSO), which exacerbates APAP-induced hepatotoxicity in rodent model $\mathrm{s}^{34,35}$. APAP at doses of 300 , 1,000 , and $2,000 \mathrm{mg} / \mathrm{kg}$ was administered orally to fasting male and female cynomolgus monkeys ( $\mathrm{n}=3-5 /$ group) pretreated intravenously with $300 \mathrm{mg} / \mathrm{kg}$ of BSO, which was administered $1 \mathrm{~h}$ before APAP treatment. Blood $(2 \mathrm{~mL} /$ time point) was collected from the femoral vein of each animal at various time points until 48 or $168 \mathrm{~h}$ after the APAP treatment. Histopathological examination was conducted $48 \mathrm{~h}$ after APAP treatment.

\section{Human relevance of APAP-induced hepatotoxicity}

APAP at $2,000 \mathrm{mg} / \mathrm{kg}$ with BSO induced hepatotoxicity in all the monkeys; the hepatotoxicity was characterized histopathologically by slight to marked centrilobular necrosis and slight periportal vacuolation of hepatocytes (Fig. 4, Table 3). Slight centrilobular necrosis was accompanied by eosinophilic degeneration of hepatocytes with pyknotic nuclei, and very slight infiltrations of neutrophils and lymphocytes mainly in the sinusoid were observed in all the monkeys. In humans, the histopathological signature of APAP-induced hepatotoxicity is very limited, but extensive centrilobular necrosis with little or no inflammation is the common finding ${ }^{36-38}$. In contrast, periportal vacuolation and centrilobular eosinophilic degeneration of hepatocytes are also reported in some cases. The pathogenesis of APAPinduced hepatotoxicity in humans remains unclear because all the above reports are from fatal APAP overdose cases. However, the major morphological features, centrilobular necrosis, caused by APAP in this monkey model is comparable to those in rodents $16,39,40$ and humans ${ }^{36-38}$. No apparent difference in susceptibility to APAP-induced hepatotoxicity was noted between the sexes. Toxicokinetic analysis revealed that the plasma APAP and N-acetyl-p-benzoquinone imine (NAPQI) concentrations increased in a dose-dependent manner. The concentrations reached a maximum at 4-7 $\mathrm{h}$ after APAP treatment and decreased to less than $1 \mu \mathrm{g} / \mathrm{mL}$ at $48 \mathrm{~h}$ after APAP treatment (Fig. 5).

Interestingly, in this monkey model of APAP-induced hepatotoxicity, plasma ALT levels did not change until 7 $\mathrm{h}$ after APAP treatment, at which time the plasma APAP and NAPQI levels had reached their peak. Plasma ALT levels increased after $24 \mathrm{~h}$ in all the monkeys, by which time APAP and NAPQI had been largely eliminated from the circulation. The lack of correlation between circulating drugs and ALT levels demonstrated in this monkey model more closely resembles the pattern found in humans than in rodents, because an increase in serum ALT levels is not usually observed until at least $12 \mathrm{~h}$ after APAP ingestion in humans ${ }^{41}$. Many processes, including the formation of NAPQI and/or protein adducts, oxidative stress, and mitochondrial permeability transition resulting in cell death, contribute to APAP-induced hepatotoxic events ${ }^{42,43}$. However, the reason for the delayed elevation of ALT and the pathogenesis of 
Table 3. Histopathology in Cynomolgus Monkeys Treated with Acetaminophen (APAP) ${ }^{32}$

\begin{tabular}{|c|c|c|c|c|c|}
\hline & & APAP & & $2,000 \mathrm{mg} / \mathrm{kg}$ & \\
\hline & & $\mathrm{BSO}$ & & $300 \mathrm{mg} / \mathrm{kg}$ & \\
\hline & & Animal No. & 04M01 & 04F01 & 04F02 \\
\hline \multirow[t]{2}{*}{ Liver } & Necrosis, hepatocyte, centrilobular area & & $3+$ & $3+$ & $1+$ \\
\hline & Vacuolation, hepatocyte, periportal area & & $1+$ & $1+$ & - \\
\hline \multirow[t]{3}{*}{ Kidney } & Vacuolation, proximal tubular epithelium & & $1+$ & $1+$ & - \\
\hline & Dilatation, distal tubule & & - & $1+$ & - \\
\hline & Hyaline cast & & - & $1+$ & - \\
\hline
\end{tabular}

APAP was administered orally to animals $1 \mathrm{~h}$ after pretreatment with L-buthionine-(S,R)-sulfoximine (BSO). All the animals, with the exception of two (04M02 and 04F03) used for the time-course analysis of hepatic biomarkers, were euthanized humanely by intravenous injection of pentobarbital sodium $(25 \mathrm{mg} / \mathrm{kg}$, somnopentyl injection) $48 \mathrm{~h}$ after APAP treatment for histopathological examination. The animals given APAP (up to 1,000 mg/kg) and BSO were morphologically normal and indistinguishable from the control animals.
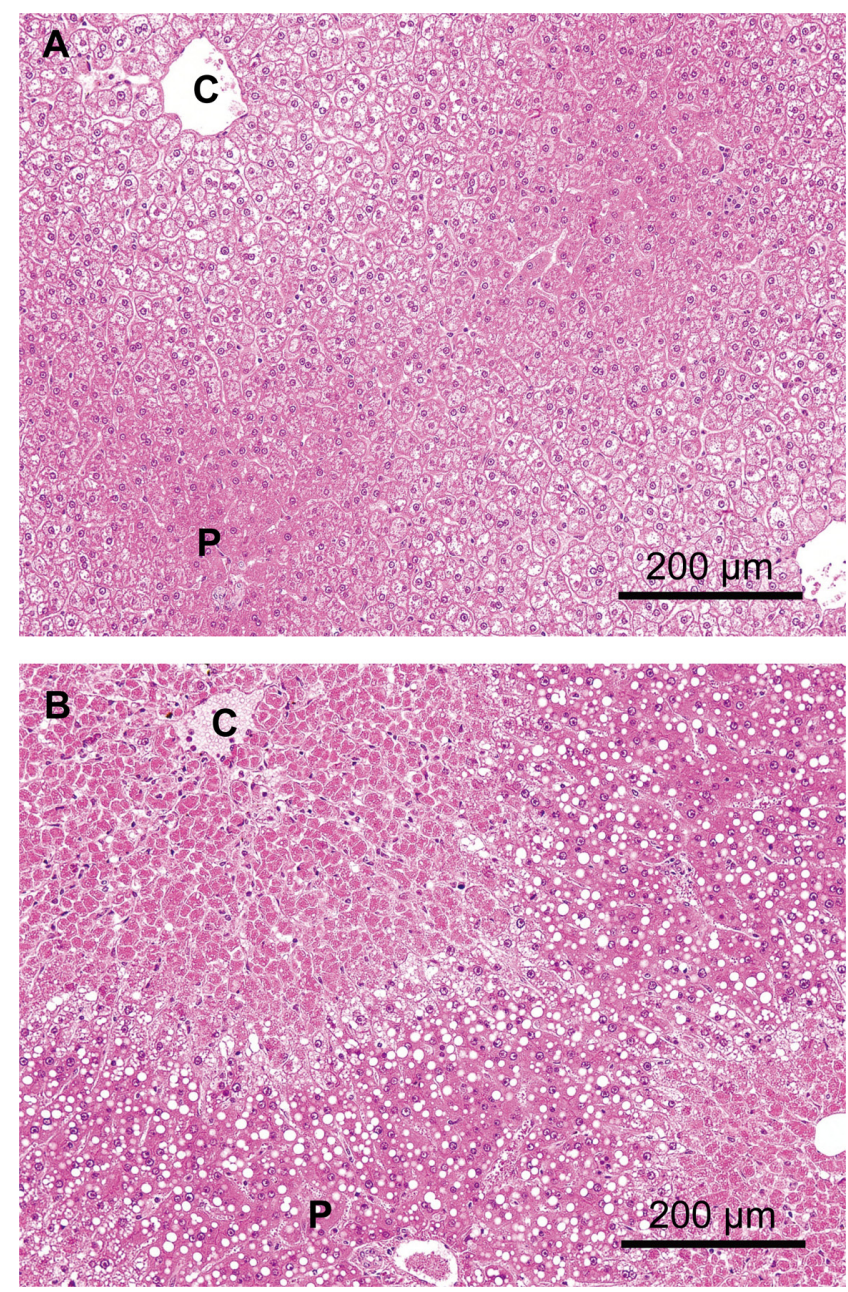

Fig. 4. Centrilobular necrosis in the liver of cynomolgus monkeys ${ }^{32}$ A: Control animal. B: Acetaminophen $(2,000 \mathrm{mg} / \mathrm{kg})$ with L-buthionine-(S,R)-sulfoximine (BSO; $300 \mathrm{mg} / \mathrm{kg}$; Animal No. 04F01). Marked necrosis and slight vacuolation of hepatocytes were seen in the centrilobular area $(\mathrm{C})$ and periportal area $(\mathrm{P})$, respectively. Hematoxylin and eosin (H\&E) stain $\times 100$.
APAP-induced hepatotoxicity in monkeys remains unclear; the complexity of the reactions occurring during APAP overdose needs to be clarified.

\section{Fluctuation in levels of circulating liver-specific miRNAs}

In this model, plasma miR-122 and miR-192 levels also increased $24 \mathrm{~h}$ or later in parallel with ALT levels. At 48 $\mathrm{h}$, the mean plasma ALT, miR-122, and miR-192 levels increased by 55 -fold, 11,600-fold, and 1,100-fold, respectively, compared with those in the vehicle control group. Although a wide interindividual variability was noted in the severity of APAP-induced hepatotoxicity, the degree of maximal increase in miR-122, miR-192, and ALT levels correlated well with that of the tissue injuries (Fig. 6, Table 3). The increment of circulating miR-122 and miR-192 levels was more prominent compared with that of ALT, indicating that circulating miR-122 and miR-192 may serve as sensitive biomarkers for the detection of hepatotoxicity in cynomolgus monkeys. Plasma ALT, miR-122, and miR-192 levels reached a maximum approximately $48 \mathrm{~h}$ after APAP treatment, although plasma miR-122 and miR-192 decreased in some animals at $48 \mathrm{~h}$. At $168 \mathrm{~h}$, the plasma ALT levels were still higher than the pre-dose values, but both the miR-122 and miR-192 levels tended to return to the pre-dose values (Fig. 6), which was similar to the pattern observed in humans $^{9,44}$. It is also important to note that the circulatory kinetics of these biomarkers in response to various types of hepatotoxicants should differ depending on their modes of action along with their half-lives in the circulation.

In the present study, a close correlation was detected among these hepatic biomarkers. The correlation coefficient was relatively high between miR-122 and miR-192 $(\mathrm{R}=0.8492, \mathrm{P}<0.01)$ compared with that between ALT and miR-122 $(\mathrm{R}=0.6541, \mathrm{P}<0.01)$ or miR-192 $(\mathrm{R}=0.6668$, $\mathrm{P}<0.01)$. Although plasma miR-192 levels are reported to increase as a result of renal ischemia reperfusion injury in rats 7 , the miR-192 levels increased in a hepatotoxicityinduced animal that had no renal toxicity (Table 3). These results suggest that the increase in miR-192 levels derived mainly from the liver. However, circulating miR-122 and/ 

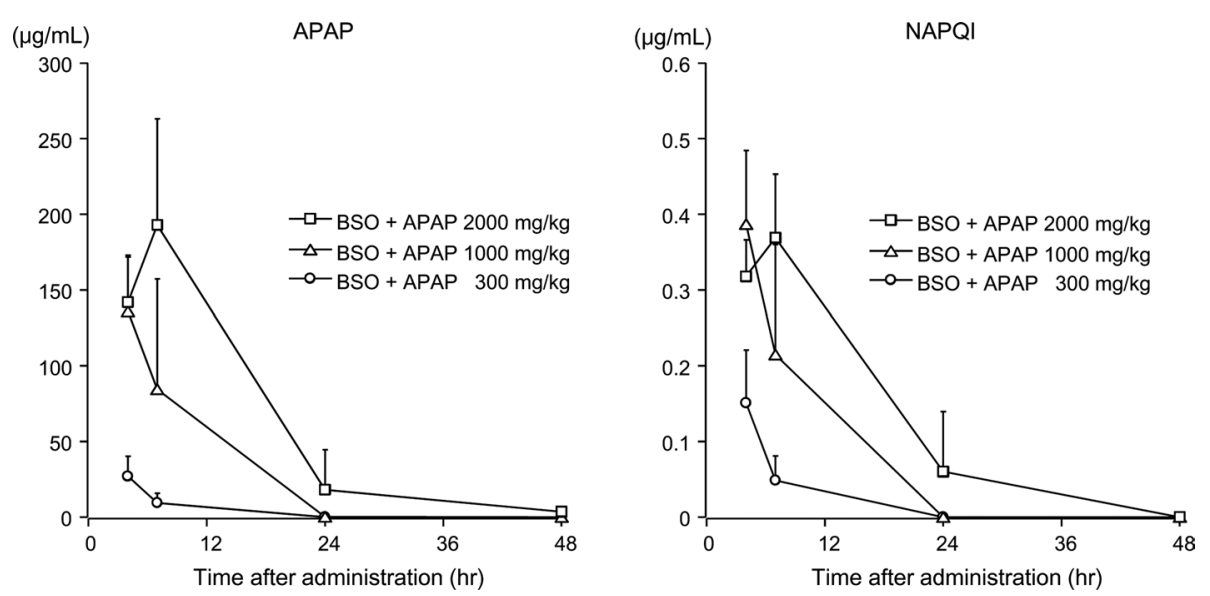

Fig. 5. Time course of plasma acetaminophen (APAP) and $N$-acetyl- $p$-benzoquinone imine (NAPQI) concentrations ${ }^{32}$. The animals were given acetaminophen at $300,1,000$, or $2,000 \mathrm{mg} / \mathrm{kg}$ with L-buthionine-(S,R)-sulfoximine (BSO; $300 \mathrm{mg} / \mathrm{kg}$ ). The data represent means + SDs.
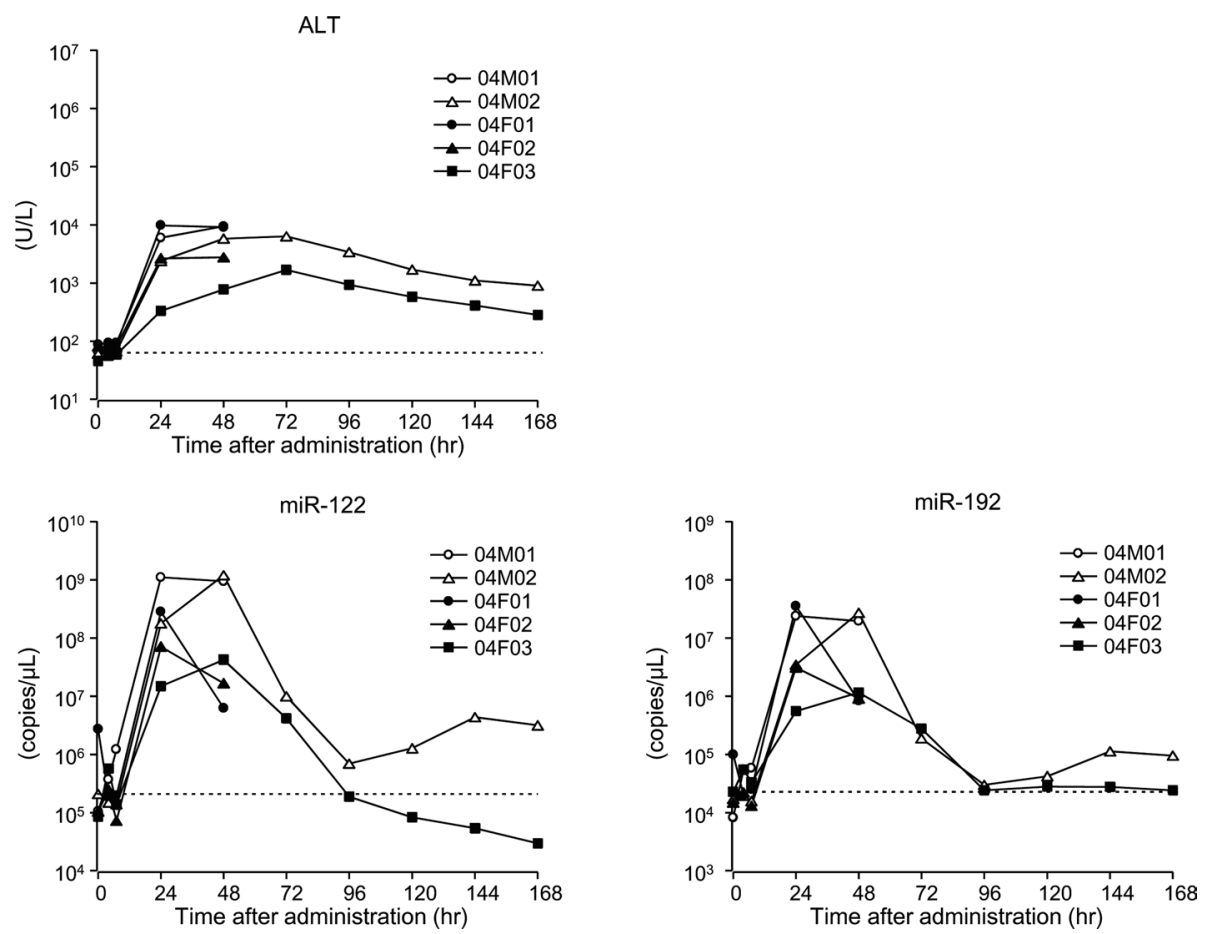

Fig. 6. Fluctuations in the levels of plasma ALT, miR-122, and miR-19232. Acetaminophen (APAP; $2,000 \mathrm{mg} / \mathrm{kg}$ ) was orally administered to animals $1 \mathrm{~h}$ after pretreatment with an intravenous injection of L-buthionine-(S,R)-sulfoximine (BSO; 300 $\mathrm{mg} / \mathrm{kg}$ ). Plasma ALT, miR-122, and miR-192 levels were measured at 0 (pre-dosing), 4, 7, 24, 48, 72, 96, 120, 144, and 168 $\mathrm{h}$ after APAP administration. Three animals were euthanized at $48 \mathrm{~h}$ for histopathological examination, and the remaining animals were used for time-course analysis. The dotted line indicates the mean of the pre-dose values in each parameter.

or miR-192 levels increase earlier compared with ALT levels in mice ${ }^{10}$ and rats $^{16}$. No blood or histopathologic samples were collected between 7 and $24 \mathrm{~h}$ after APAP treatment in our study. Therefore, further investigation into the timecourse response of miR-122 and miR-192 levels and related changes in the liver during this time period in this model is necessary to address this point.

\section{Discussion}

Among the more than 1000 mature miRNAs identified by NGS analysis in the 27 tissues and organs from cynomolgus monkeys, in this review, we focused on the liver-specific/enriched miRNAs that are thought to be associated with tissue injury. It has been reported that many 
miRNAs are conserved among mammalian species ${ }^{8}$. In the cynomolgus monkeys, both miR-122 and miR-192 exhibited $100 \%$ sequence homology with the respective miRNAs of other species, including humans, mice, rats, dogs, and zebrafish registered in miRBase (Release 21.0). Our NGS analysis also suggested that miR-122 was the most specific miRNA in the liver, and miR-192 was the most abundant. In contrast, the data that have been evaluated in human livers using deep sequencing methods indicated that miR-122 was more abundant than miR-19245, 46. Although this inconsistency could have derived from different platforms and analysis procedures, further characterization is necessary to evaluate translatability from monkeys to humans. As for other organ-specific circulating miRNAs than those of the liver, skeletal muscle-, heart-, and intestine-specific circulating miRNAs have been proposed as potential biomarkers for tissue injuries in the respective organs in other species including humans ${ }^{4}, 5,18,47$. These organ-specific miRNAs in cynomolgus monkeys will be clarified in the near future.

In a clinical setting, the plasma APAP concentration measured 4-24 $\mathrm{h}$ after ingestion is the basis for the diagnosis of liver toxicity according to the Rumack-Matthew nomogram ${ }^{48,49}$. To decrease the risk of hepatotoxicity, early administration $(<8 \mathrm{~h}$ post-ingestion) of $\mathrm{N}$-acetylcysteine (NAC) as the antidote is vital ${ }^{50,51}$. Therefore, new biomarkers for pre-detecting APAP toxicity earlier than by the current approach are urgently required. In the present review, we have addressed the fundamental profiles of circulating liver-specific miRNAs in cynomolgus monkeys, using an APAP-induced hepatotoxicity model, which demonstrated greater phenotypic similarity to humans than to rodents. Regarding the fluctuation in circulating miRNA levels, however, the elevation of plasma miR-122 and miR-192 levels was not observed $7 \mathrm{~h}$ after dosing, which was in parallel with the ALT levels. Similarly, the early onset of circulating miR-122 and/or miR-192 levels has rarely been reported in humans except in limited case reports ${ }^{17,52}$. These data suggest further challenges in bridging the gap between preclinical and clinical studies.

According to the current paradigm, extracellular miRNAs are derived from the tissue by either passive leakage through apoptosis and necrosis or through active secretion via microvesicles including exosomes ${ }^{53}$. Of note, we found that the extent of miRNA expression in the predominant organs was not reflected in the circulating miRNA levels. There was an approximately 8-fold higher mean miR-122 plasma level compared with that for miR-192, whereas the counts in the liver for miR-122 were lower than those for miR-192. Such inconsistencies may suggest that detectable miRNAs in the plasma are secreted actively via microvesicles, such as exosomes, to play a role in cell-to-cell communication ${ }^{54}$. In fact, hepatic exosomes could be the source of the organ-specific miRNAs that are involved in various liver functions ${ }^{55}$. Although a higher baseline concentration of circulating miRNAs could be caused by differences in circulation stability or differences in the clearance level, extracellular miRNAs may contribute to certain physiological and pathological activities of target cells. Therefore, further investigation is necessary to clarify the above inconsistency.

Recent studies have shown that extracellular miRNAs are associated with Ago complexes or are packaged inside exosomes in cell lines or in healthy human plasma ${ }^{56,57}$. Bala et al. ${ }^{55}$ examined the fate of extracellular miRNAs following cellular damage by using various liver injury mouse models. In their study, inflammatory liver injury and APAP-induced liver injury increased serum/plasma miR-122 predominantly associated with exosome-rich and protein-rich fractions, respectively. Furthermore, Momen-Heravi et al. 58 found a strong linear correlation between exosome numbers and ALT levels, indicating that an increase in exosome numbers mirrors the hepatocellular damage induced by ethanol. In contrast, Vliegenthart ${ }^{44}$ reported that human miR-122 circulates in a form that is bound to the protein Ago2 and that this fraction increases with liver injury. All miRNAs were extracted from unfractionated plasma in our studies; therefore, further investigation with fractionated extracellular miRNAs at various time points in tissue-injury models will be necessary.

\section{Conclusion}

In conclusion, we profiled liver-specific circulating miRNAs in cynomolgus monkeys by NGS and RT-qPCR. Although the basal plasma miRNA levels revealed potential confounding factors other than sex, the miRNA levels increased far above their reference ranges in the hepatotoxicity model. The present studies suggest that investigation of circulating miRNAs in cynomolgus monkeys provides valuable information on translational biomarkers to diagnose DILI in humans.

Disclosure of Potential Conflicts of Interest: The authors declare that there is no conflict of interest with respect to the research, authorship, and/or publication of this article.

Acknowledgments: This research did not receive any specific grant from funding agencies in the public, commercial, or not-for-profit sectors.

\section{References}

1. Bhaskaran M, and Mohan M. MicroRNAs: history, biogenesis, and their evolving role in animal development and disease. Vet Pathol. 51: 759-774. 2014. [Medline] [CrossRef]

2. Chen X, Ba Y, Ma L, Cai X, Yin Y, Wang K, Guo J, Zhang Y, Chen J, Guo X, Li Q, Li X, Wang W, Zhang Y, Wang J, Jiang X, Xiang Y, Xu C, Zheng P, Zhang J, Li R, Zhang $\mathrm{H}$, Shang X, Gong T, Ning G, Wang J, Zen K, Zhang J, and Zhang CY. Characterization of microRNAs in serum: a novel class of biomarkers for diagnosis of cancer and other diseases. Cell Res. 18: 997-1006. 2008. [Medline] [CrossRef]

3. Turchinovich A, Samatov TR, Tonevitsky AG, and Burwinkel B. Circulating miRNAs: cell-cell communication function? Front Genet. 4: 119. 2013. [Medline] [CrossRef] 
4. Laterza OF, Lim L, Garrett-Engele PW, Vlasakova K, Muniappa N, Tanaka WK, Johnson JM, Sina JF, Fare TL, Sistare FD, and Glaab WE. Plasma MicroRNAs as sensitive and specific biomarkers of tissue injury. Clin Chem. 55: 1977-1983. 2009. [Medline] [CrossRef]

5. Corsten MF, Dennert R, Jochems S, Kuznetsova T, Devaux Y, Hofstra L, Wagner DR, Staessen JA, Heymans S, and Schroen B. Circulating MicroRNA-208b and MicroRNA-499 reflect myocardial damage in cardiovascular disease. Circ Cardiovasc Genet. 3: 499-506. 2010. [Medline] [CrossRef]

6. Tsujiura M, Ichikawa D, Komatsu S, Shiozaki A, Takeshita H, Kosuga T, Konishi H, Morimura R, Deguchi K, Fujiwara $\mathrm{H}$, Okamoto $\mathrm{K}$, and Otsuji E. Circulating microRNAs in plasma of patients with gastric cancers. Br J Cancer. 102: 1174-1179. 2010. [Medline] [CrossRef]

7. Zhang L, Xu Y, Xue S, Wang X, Dai H, Qian J, Ni Z, and Yan Y. Implications of dynamic changes in miR-192 expression in ischemic acute kidney injury. Int Urol Nephrol. 49: 541-550. 2017. [Medline] [CrossRef]

8. Ambros V. The functions of animal microRNAs. Nature. 431: 350-355. 2004. [Medline] [CrossRef]

9. Starkey Lewis PJ, Dear J, Platt V, Simpson KJ, Craig DG, Antoine DJ, French NS, Dhaun N, Webb DJ, Costello EM, Neoptolemos JP, Moggs J, Goldring CE, and Park BK. Circulating microRNAs as potential markers of human drug-induced liver injury. Hepatology. 54: 1767-1776. 2011. [Medline] [CrossRef]

10. Wang K, Zhang S, Marzolf B, Troisch P, Brightman A, Hu Z, Hood LE, and Galas DJ. Circulating microRNAs, potential biomarkers for drug-induced liver injury. Proc Natl Acad Sci USA. 106: 4402-4407. 2009. [Medline] [CrossRef]

11. Carlsson HE, Schapiro SJ, Farah I, and Hau J. Use of primates in research: a global overview. Am J Primatol. 63: 225-237. 2004. [Medline] [CrossRef]

12. Yan G, Zhang G, Fang X, Zhang Y, Li C, Ling F, Cooper DN, Li Q, Li Y, van Gool AJ, Du H, Chen J, Chen R, Zhang P, Huang Z, Thompson JR, Meng Y, Bai Y, Wang J, Zhuo M, Wang T, Huang Y, Wei L, Li J, Wang Z, Hu H, Yang P, Le L, Stenson PD, Li B, Liu X, Ball EV, An N, Huang Q, Zhang Y, Fan W, Zhang X, Li Y, Wang W, Katze MG, Su B, Nielsen R, Yang H, Wang J, Wang X, and Wang J. Genome sequencing and comparison of two nonhuman primate animal models, the cynomolgus and Chinese rhesus macaques. Nat Biotechnol. 29: 1019-1023. 2011. [Medline] [CrossRef]

13. Emoto C, Yoda N, Uno Y, Iwasaki K, Umehara K, Kashiyama E, and Yamazaki H. Comparison of p450 enzymes between cynomolgus monkeys and humans: p450 identities, protein contents, kinetic parameters, and potential for inhibitory profiles. Curr Drug Metab. 14: 239-252. 2013. [Medline]

14. Platt R, Madre L, Reynolds R, and Tilson H. Active drug safety surveillance: a tool to improve public health. Pharmacoepidemiol Drug Saf. 17: 1175-1182. 2008. [Medline] [CrossRef]

15. Church RJ, Otieno M, McDuffie JE, Singh B, Sonee M, Hall L, Watkins PB, Ellinger-Ziegelbauer H, and Harrill AH. Beyond miR-122: identification of MicroRNA alterations in blood during a time course of hepatobiliary injury and biliary hyperplasia in rats. Toxicol Sci. 150: 3-14. 2016. [Medline] [CrossRef]
16. Yamaura Y, Nakajima M, Takagi S, Fukami T, Tsuneyama $\mathrm{K}$, and Yokoi T. Plasma microRNA profiles in rat models of hepatocellular injury, cholestasis, and steatosis. PLoS One. 7: e30250. 2012. [Medline] [CrossRef]

17. Dear JW, Antoine DJ, Starkey-Lewis P, Goldring CE, and Park BK. Early detection of paracetamol toxicity using circulating liver microRNA and markers of cell necrosis. Br J Clin Pharmacol. 77: 904-905. 2014. [Medline] [CrossRef]

18. Calvano J, Achanzar W, Murphy B, DiPiero J, Hixson C, Parrula C, Burr H, Mangipudy R, and Tirmenstein M. Evaluation of microRNAs-208 and $133 \mathrm{a} / \mathrm{b}$ as differential biomarkers of acute cardiac and skeletal muscle toxicity in rats. Toxicol Appl Pharmacol. 312: 53-60. 2016. [Medline] [CrossRef]

19. Moldovan L, Batte KE, Trgovcich J, Wisler J, Marsh CB, and Piper M. Methodological challenges in utilizing miRNAs as circulating biomarkers. J Cell Mol Med. 18: $371-$ 390. 2014. [Medline] [CrossRef]

20. Veeranagouda Y, Rival P, Prades C, Mariet C, Léonard JF, Gautier JC, Zhou X, Wang J, Li B, Ozoux ML, and Boitier E. Identification of microRNAs in Macaca fascicularis (cynomolgus monkey) by homology search and experimental validation by small RNA-Seq and RT-qPCR using kidney cortex tissues. PLoS One. 10: e0142708. 2015. [Medline] [CrossRef]

21. Sakurai K, Mikamoto K, Shirai M, Iguchi T, Ito K, Takasaki W, and Mori K. MicroRNA profiles in a monkey testicular injury model induced by testicular hyperthermia. J Appl Toxicol. 36: 1614-1621. 2016. [Medline] [CrossRef]

22. Iguchi T, Niino N, Tamai S, Sakurai K, and Mori K. Comprehensive analysis of circulating microRNA specific to the liver, heart, and skeletal muscle of cynomolgus monkeys. Int J Toxicol. 36: 220-228. 2017. [Medline] [CrossRef]

23. Smith A, Calley J, Mathur S, Qian HR, Wu H, Farmen M, Caiment F, Bushel PR, Li J, Fisher C, Kirby P, Koenig E, Hall DG, and Watson DE. The Rat microRNA body atlas; Evaluation of the microRNA content of rat organs through deep sequencing and characterization of pancreas enriched miRNAs as biomarkers of pancreatic toxicity in the rat and dog. BMC Genomics. 17: 694. 2016. [Medline] [CrossRef]

24. Koenig EM, Fisher C, Bernard H, Wolenski FS, Gerrein J, Carsillo M, Gallacher M, Tse A, Peters R, Smith A, Meehan A, Tirrell S, and Kirby P. The beagle dog MicroRNA tissue atlas: identifying translatable biomarkers of organ toxicity. BMC Genomics. 17: 649. 2016. [Medline] [CrossRef]

25. Tian Z, Greene AS, Pietrusz JL, Matus IR, and Liang M. MicroRNA-target pairs in the rat kidney identified by microRNA microarray, proteomic, and bioinformatic analysis. Genome Res. 18: 404-411. 2008. [Medline] [CrossRef]

26. Pritchard CC, Cheng HH, and Tewari M. MicroRNA profiling: approaches and considerations. Nat Rev Genet. 13: 358-369. 2012. [Medline] [CrossRef]

27. Bland JM, and Altman DG. Transformations, means, and confidence intervals. BMJ. 312: 1079. 1996. [Medline] [CrossRef]

28. Akiyama H, Ueda $\mathrm{Y}$, Nobumasa $\mathrm{H}$, Ooshima $\mathrm{H}$, Ishizawa $\mathrm{Y}$, Kitahiro K, Miyagawa I, Watanabe K, Nakamura T, Tanaka R, Yamamoto N, Nakae H, Kawase M, Gemma N, Sekiguchi Y, Fujibuchi W, and Matoba R. A set of external reference controls/probes that enable quality assurance between different microarray platforms. Anal Biochem. 472: 75-83. 2015. [Medline] [CrossRef] 
29. Malentacchi F, Pazzagli M, Simi L, Orlando C, Wyrich R, Günther K, Verderio P, Pizzamiglio S, Ciniselli CM, Zhang H, Korenková V, Rainen L, Bar T, Kubista M, and Gelmini S. SPIDIA-RNA: second external quality assessment for the pre-analytical phase of blood samples used for RNA based analyses. PLoS One. 9: e112293. 2014. [Medline] [CrossRef]

30. Davis DC, Potter WZ, Jollow DJ, and Mitchell JR. Species differences in hepatic glutathione depletion, covalent binding and hepatic necrosis after acetaminophen. Life Sci. 14: 2099-2109. 1974. [Medline] [CrossRef]

31. Tee LB, Davies DS, Seddon CE, and Boobis AR. Species differences in the hepatotoxicity of paracetamol are due to differences in the rate of conversion to its cytotoxic metabolite. Biochem Pharmacol. 36: 1041-1052. 1987. [Medline] [CrossRef]

32. Tamai S, Iguchi T, Niino N, Mikamoto K, Sakurai K, Sayama A, Shimoda H, Takasaki W, and Mori K. A monkey model of acetaminophen-induced hepatotoxicity; phenotypic similarity to human. J Toxicol Sci. 42: 73-84. 2017. [Medline] [CrossRef]

33. Smolarek TA, Higgins CV, and Amacher DE. Metabolism and cytotoxicity of acetaminophen in hepatocyte cultures from rat, rabbit, dog, and monkey. Drug Metab Dispos. 18: 659-663. 1990. [Medline]

34. Miners JO, Drew R, and Birkett DJ. Mechanism of action of paracetamol protective agents in mice in vivo. Biochem Pharmacol. 33: 2995-3000. 1984. [Medline] [CrossRef]

35. Watanabe T, Sagisaka H, Arakawa S, Shibaya Y, Watanabe M, Igarashi I, Tanaka K, Totsuka S, Takasaki W, and Manabe $\mathrm{S}$. A novel model of continuous depletion of glutathione in mice treated with L-buthionine (S,R)-sulfoximine. J Toxicol Sci. 28: 455-469. 2003. [Medline] [CrossRef]

36. Ramachandran R, and Kakar S. Histological patterns in drug-induced liver disease. J Clin Pathol. 62: 481-492. 2009. [Medline] [CrossRef]

37. Davidson DG, and Eastham WN. Acute liver necrosis following overdose of paracetamol. BMJ. 2: 497-499. 1966. [Medline] [CrossRef]

38. McJunkin B, Barwick KW, Little WC, and Winfield JB. Fatal massive hepatic necrosis following acetaminophen overdose. JAMA. 236: 1874-1875. 1976. [Medline] [CrossRef]

39. Heinloth AN, Irwin RD, Boorman GA, Nettesheim P, Fannin RD, Sieber SO, Snell ML, Tucker CJ, Li L, Travlos GS, Vansant G, Blackshear PE, Tennant RW, Cunningham ML, and Paules RS. Gene expression profiling of rat livers reveals indicators of potential adverse effects. Toxicol Sci. 80: 193-202. 2004. [Medline] [CrossRef]

40. Starckx S, Batheja A, Verheyen GR, Jonghe SD, Steemans K, Dijck BV, Singer M, Bogdan N, Snoeys J, Vinken P, Sasaki JC, Gompel JV, Guzzie-Peck P, Lampo A, and Lammens L. Evaluation of miR-122 and other biomarkers in distinct acute liver injury in rats. Toxicol Pathol. 41: 795-804. 2013. [Medline] [CrossRef]

41. Hornby RJ, Starkey Lewis P, Dear J, Goldring C, and Park BK. MicroRNAs as potential circulating biomarkers of drug-induced liver injury: key current and future issues for translation to humans. Expert Rev Clin Pharmacol. 7: 349-362. 2014. [Medline] [CrossRef]

42. Hinson JA, Roberts DW, and James LP. Mechanisms of acetaminophen-induced liver necrosis. Handb Exp Pharmacol. 196: 369-405. 2010. [Medline] [CrossRef]
43. Masubuchi Y, Suda C, and Horie T. Involvement of mitochondrial permeability transition in acetaminophen-induced liver injury in mice. J Hepatol. 42: 110-116. 2005. [Medline] [CrossRef]

44. Vliegenthart AD, Shaffer JM, Clarke JI, Peeters LE, Caporali A, Bateman DN, Wood DM, Dargan PI, Craig DG, Moore JK, Thompson AI, Henderson NC, Webb DJ, Sharkey J, Antoine DJ, Park BK, Bailey MA, Lader E, Simpson KJ, and Dear JW. Comprehensive microRNA profiling in acetaminophen toxicity identifies novel circulating biomarkers for human liver and kidney injury. Sci Rep. 5: 15501. 2015. [Medline] [CrossRef]

45. Hou J, Lin L, Zhou W, Wang Z, Ding G, Dong Q, Qin L, Wu X, Zheng Y, Yang Y, Tian W, Zhang Q, Wang C, Zhang Q, Zhuang SM, Zheng L, Liang A, Tao W, and Cao X. Identification of miRNomes in human liver and hepatocellular carcinoma reveals miR-199a/b-3p as therapeutic target for hepatocellular carcinoma. Cancer Cell. 19: 232-243. 2011. [Medline] [CrossRef]

46. Wang W, Shi Q, Mattes WB, Mendrick DL, and Yang X. Translating extracellular microRNA into clinical biomarkers for drug-induced toxicity: from high-throughput profiling to validation. Biomarkers Med. 9: 1177-1188. 2015. [Medline] [CrossRef]

47. Kalabat DY, Vitsky A, Scott W, Kindt E, Hayes K, JohnBaptiste A, Huang W, and Yang AH. Identification and Evaluation of Novel MicroRNA Biomarkers in Plasma and Feces Associated with Drug-induced Intestinal Toxicity. Toxicol Pathol. 45: 302-320. 2017. [Medline] [CrossRef]

48. Rumack BH, and Matthew H. Acetaminophen poisoning and toxicity. Pediatrics. 55: 871-876. 1975. [Medline]

49. Heard KJ. Acetylcysteine for acetaminophen poisoning. N Engl J Med. 359: 285-292. 2008. [Medline] [CrossRef]

50. Smilkstein MJ, Knapp GL, Kulig KW, and Rumack BH. Efficacy of oral $\mathrm{N}$-acetylcysteine in the treatment of acetaminophen overdose. Analysis of the national multicenter study (1976 to 1985). N Engl J Med. 319: 1557-1562. 1988. [Medline] [CrossRef]

51. Prescott LF, Illingworth RN, Critchley JA, Stewart MJ, Adam RD, and Proudfoot AT. Intravenous N-acetylcystine: the treatment of choice for paracetamol poisoning. BMJ. 2: 1097-1100. 1979. [Medline] [CrossRef]

52. Thulin P, Nordahl G, Gry M, Yimer G, Aklillu E, Makonnen E, Aderaye G, Lindquist L, Mattsson CM, Ekblom B, Antoine DJ, Park BK, Linder S, Harrill AH, Watkins PB, Glinghammar B, and Schuppe-Koistinen I. Keratin-18 and microRNA-122 complement alanine aminotransferase as novel safety biomarkers for drug-induced liver injury in two human cohorts. Liver Int. 34: 367-378. 2014. [Medline] [CrossRef]

53. Turchinovich A, Weiz L, Langheinz A, and Burwinkel B. Characterization of extracellular circulating microRNA. Nucleic Acids Res. 39: 7223-7233. 2011. [Medline] [CrossRef]

54. Chen X, Liang H, Zhang J, Zen K, and Zhang CY. Secreted microRNAs: a new form of intercellular communication. Trends Cell Biol. 22: 125-132. 2012. [Medline] [CrossRef]

55. Bala S, Petrasek J, Mundkur S, Catalano D, Levin I, Ward J, Alao H, Kodys K, and Szabo G. Circulating microRNAs in exosomes indicate hepatocyte injury and inflammation in alcoholic, drug-induced, and inflammatory liver diseases. Hepatology. 56: 1946-1957. 2012. [Medline] [CrossRef] 
56. Arroyo JD, Chevillet JR, Kroh EM, Ruf IK, Pritchard CC, Gibson DF, Mitchell PS, Bennett CF, Pogosova-Agadjanyan EL, Stirewalt DL, Tait JF, and Tewari M. Argonaute2 complexes carry a population of circulating microRNAs independent of vesicles in human plasma. Proc Natl Acad Sci USA. 108: 5003-5008. 2011. [Medline] [CrossRef]

57. Ohshima K, Inoue K, Fujiwara A, Hatakeyama K, Kanto K, Watanabe Y, Muramatsu K, Fukuda Y, Ogura S, Yamaguchi $\mathrm{K}$, and Mochizuki T. Let-7 microRNA family is selectively secreted into the extracellular environment via exosomes in a metastatic gastric cancer cell line. PLoS One. 5: e13247. 2010. [Medline] [CrossRef]

58. Momen-Heravi F, Saha B, Kodys K, Catalano D, Satishchandran A, and Szabo G. Increased number of circulating exosomes and their microRNA cargos are potential novel biomarkers in alcoholic hepatitis. J Transl Med. 13: 261. 2015. [Medline] [CrossRef] 